2017 Zone I Best Paper: Molecules and Cells: A Model for Addressing the Needs of Students with Varied Backgrounds and Diverse Learning Styles

Dr. Eileen Haase Ph.D., Johns Hopkins University

Dr. Haase is a senior lecturer at Johns Hopkins University in the Department of Biomedical Engineering and chair of the Applied Biomedical Engineering program. She is currently the interim Director of Undergraduate Studies.

Dr. Harry R. Goldberg, Johns Hopkins University 


\title{
Molecules and Cells: a model for addressing the needs of students with varied backgrounds and diverse learning styles
}

\author{
Eileen Haase and Harry Goldberg \\ Johns Hopkins University Department of Biomedical Engineering
}

\begin{abstract}
Students in "Molecules and Cells" completed a survey to assess their learning preferences. Almost two-thirds of the students were multimodal, learning through a combination of visual, aural, read/write, or kinesthetic modes. This supported our view that a diverse learning environment with a variety of learning modalities would make a significant contribution to the students' understanding and retention of the material. These methods included: lectures with class demonstrations, team based learning, formative assessments through "clicker questions", simulations, peer instruction, informal and formal group discussion, case studies, and a variety of online resources. A majority (93\%) of students believed they benefitted from this approach, a view that was supported quantitatively: $90 \%$ of the 126 students enrolled in the course attended class even though each lecture was available on-line.
\end{abstract}

Background

The Johns Hopkins Biomedical Engineering (BME) course Molecules and Cells is taught primarily to sophomore students in BME. For most students, it is their first challenging BME course, combining both biochemistry and cell biology with quantitative analysis. From the faculty's perspective, Molecules and Cells has the added complexity of student heterogeneity: almost half of the students completed AP Biology in high school, while many only have a weak biology background. At the start of the course, the students were asked to complete a survey used to assess their learning preferences ${ }^{1}$. Almost two-thirds of the students (62\%) were multimodal, learning through a combination of visual, aural, read/write, or kinesthetic modes. For the $38 \%$ of students who preferred a single learning style, most preferred read/write (18\%) modes of learning. Only $3 \%$ of students had an aural learning preference, while $9 \%$ had a visual learning preference, and 8\% leaned towards kinesthetic (Fig. 1). We used this information to support our view that a diverse learning environment with a variety of activities would significantly enhance the students' understanding of the material, regardless of their learning preference. Given the class' heterogeneity in both background knowledge and learning preferences, we added numerous online resources, many of which we generated specifically for this purpose, for students who needed additional assistance learning core concepts. These resources included videos, ungraded quizzes, and simulations. During lectures, we incorporated clicker questions ${ }^{2,3}$ and team based discussions ${ }^{4}$, both proven techniques used to improve knowledge acquisition in an active learning environment. Finally, we added in-class exercises, such as a student demonstration of oxidative phosphorylation, discussion of clinical case studies, and think/pair/share problems where students were given a question, they thought about the solution, and then discussed possible answers with a colleague 5 . Though all lectures were recorded and made available online, class attendance remained high which we believe is a function of the rich learning environment that characterized Molecules and Cells. 


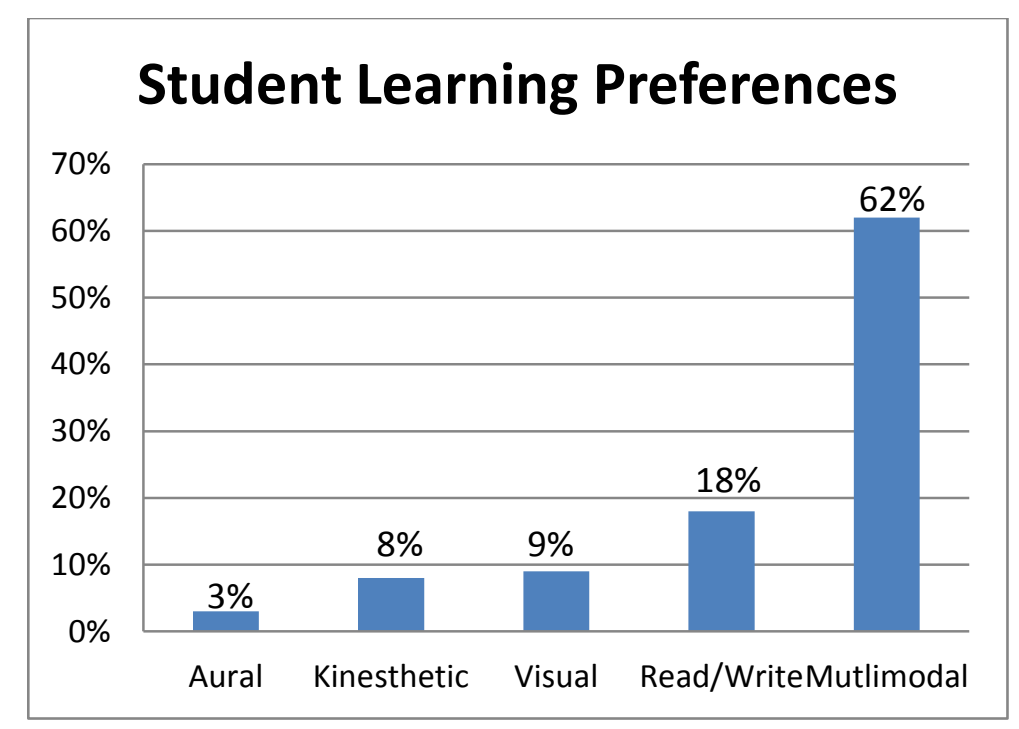

Figure 1: Data from VARK survey on student learning preferences $(n=99)$ in Molecules and Cells. Most students (62\%) were multimodal, learning through a combination of visual, aural, $\mathrm{read} / \mathrm{write}$, or kinesthetic modes. For the students who preferred a single learning style, $18 \%$ preferred to learn through read/write activities, $9 \%$ visual, $8 \%$ kinesthetic, and $3 \%$ aural.

\section{Course Structure}

The course met three times a week for fifty minutes, with an additional TA-guided section one day a week. Mondays and Wednesdays were used for lectures with frequent clicker questions, think/pair/share activities, and demonstrations. Fridays were used for team based learning and clinical/research discussions. First exposure to each week's course material was usually through short videos, simulations, and animations. A sample week is illustrated in Fig 2.

\section{Sample "Molecules and Cells" Week}

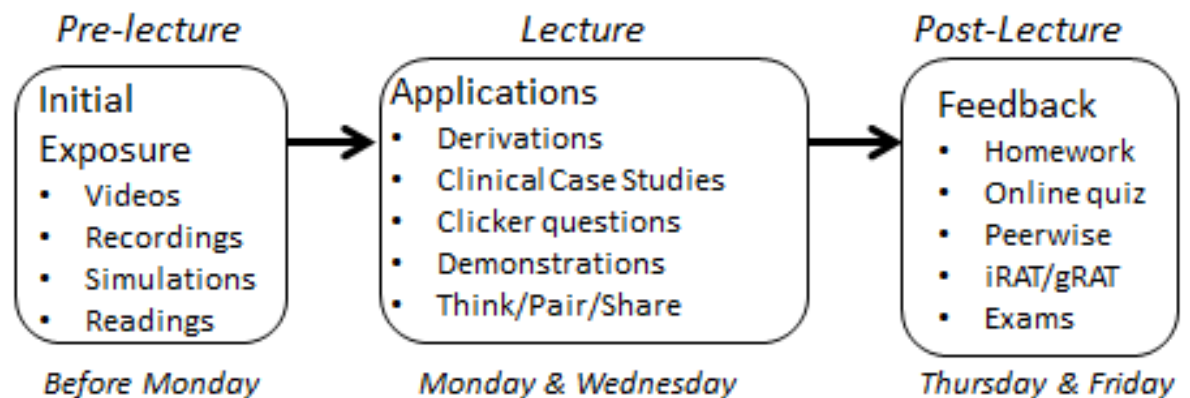

Pre-lecture: Read/view material on enzyme kinetics, enzyme inhibition, allosteric modification
Lecture: Derive Michaelis-Menton \& Lineweaver-Burk equations and graph results. Discuss deadly effect of enzyme inhibition from a nerve gas, such as Sarin, and positive effects of enzyme inhibition with AZT in treating AIDs or ethanol in treating methanol poisoning

Figure 2: Sample week depicting the variety of teaching methods for enzymes 
For example, during the module on Enzymes, students view short videos, read sections of the textbooks, and/or practice using simulations to gain an introduction to enzyme kinetics, competitive and non-competitive inhibition, and allosteric modification. Lecture time is used to derive equations and graph data with various inhibitors and activators, while incorporating the use of clicker questions. Lectures include clinical case discussions which engage students in active learning on such topics as the enzyme inhibitor Sarin, a deadly nerve gas, the drug AZT, an HIV replication inhibitor, and the use of ethanol to counteract methanol poisoning.

We were awarded two Technology Fellowships from the Johns Hopkins University Center for Education Resources to develop online resources specifically for Molecules and Cells. Ten videos and two simulations were created by our own students as instructional aids to cover material not readily available through other sources. In addition, we developed a library with links to relevant videos and simulations posted on YouTube, access to the Kinemage ${ }^{5}$ protein visualization simulation, and links to videos from the textbook publishers ${ }^{6,7}$. While some of these links were available only through Blackboard, Johns Hopkins' platform for course-based websites, most were YouTube videos with links within the course syllabus and aligned, week by week, with the course material. Textbook readings were also assigned as some students preferred this method of learning. Class time was used to discuss applications and to work on mathematical problems which were not found in the suggested textbooks.

Individual Learning

Access to Blackboard is the primary vehicle for individual learning. During the course of the fall 2015 semester, students $(n=136)$ accessed Blackboard 32,055 times, an average of 232 views per student. On average, each student logged into Blackboard approximately 17 times a week. Using Blackboard's "Statistics Tracking" feature allowed us to see which students used each resource over the course of the semester, as well as what day, and even what time, they accessed the material. A summary of the Blackboard date for the entire semester is shown in the Fig 3 below. It is evident from the data that homework was due on Thursday mornings.

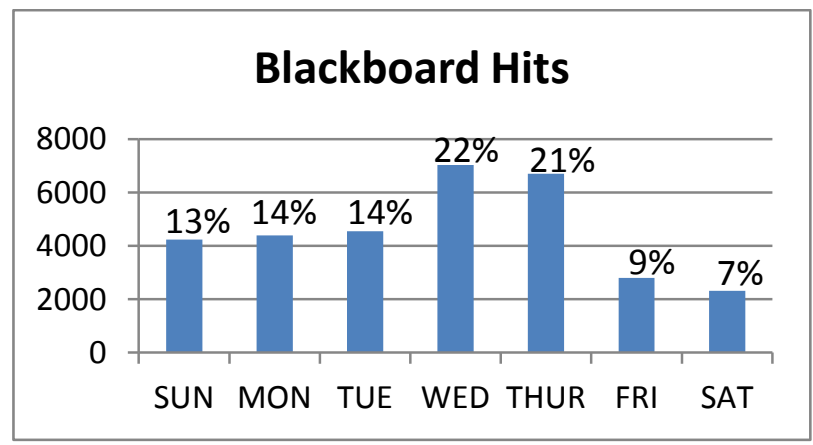

Figure 3: Students accessed the Blackboard site over 32,000 times, an average of 232 views per student during one semester of Molecules and Cells.

The Blackboard course site and syllabus links provide access to over 100 videos, animations, and simulations. The videos are generally under five minutes and give the student a quick first exposure to the terms and concepts which will be covered in more depth during the lecture. 
Based on survey data, $30 \%$ of the students took advantage of these online resources. The simulations on Blackboard allowed students to work through multiple scenarios, such as the effect of varying concentrations of an enzyme inhibitor on product formation, or the effect of glucose on activation of the lac operon. We also recorded all of the fifty-minute lectures using Panopto $^{8}$, and posted the links, as well as pdf copies of the slides on the course website through Blackboard. Two-thirds of students regularly viewed these recorded lectures.

In addition to watching videos, students also appreciated having opportunities for selfassessment through ungraded online quizzes also available on Blackboard. Each week a new quiz was presented, along with cumulative quizzes prior to each exam. Questions were randomly chosen from a large test bank, so that students could take these quizzes multiple times without repeating questions. Over half of the students challenged themselves with these weekly quizzes. We also had each student post one multiple choice question for the rest of the class prior to each exam, three times during the semester, to develop a test bank of questions on Peerwise ${ }^{9}$. Over a three year period, our students generated over 1,100 multiple choice questions. We vetted and added the most helpful questions to our online bank of test questions for the ungraded quizzes. A significant $(23 \%)$ group of students answered an average of 117 Peerwise questions $(\sim 10$ per week) over the course of the semester, answering almost 9,000 Peerwise questions over a three year period. The combination of the ungraded quizzes on Blackboard, and the multiple choice questions on Peerwise, allowed students to work through problems and have an unlimited number of opportunities for problem solving. Since these problems were all designed specifically for the JHU Molecules and Cells course they allowed students to focus their attention on the material emphasized in class. The variety of learning options and their self-reported use by students $(\mathrm{n}=327)$ over a three year period is given in Table 1.

Table 1

Learning Mechanisms

\begin{tabular}{|l|l|}
\hline Attended Lectures & $89 \%$ \\
\hline Viewed lecture online (Panopto) & $66 \%$ \\
\hline Downloaded and reviewed slides and lecture notes & $93 \%$ \\
\hline Viewed short videos/simulations posted on Blackboard & $30 \%$ \\
\hline Attended Thursday section & $65 \%$ \\
\hline Attended office hours with TAs and/or faculty & $22 \%$ \\
\hline Took online self-check quizzes (ungraded) & $55 \%$ \\
\hline Worked with a study group & $63 \%$ \\
\hline Answered extra Peerwise questions & $23 \%$ \\
\hline
\end{tabular}

\section{Lecture Structure}

Lectures allowed faculty time to augment textbook material with current research, analyze sample data, and work through sample problems. In order to assess student understanding in a real-time manner, faculty posed an average of 2.7 clicker questions each lecture. Many of the clicker questions were shown twice, once for students to complete individually, and a second time after a brief discussion with a classmate. Over a three year period, $92 \%$ of students surveyed requested the same number or even more clicker questions, as they believed this helped with 
comprehension and overall retention of the material. We recorded clicker activity and students received a participation grade worth a very small percentage $(<1 \%)$ of their final grade. Giving even a small amount of credit for answering clicker questions encouraged students to stay engaged during the lecture.

We also implemented a variety of lecture activities, some of which are listed in Table 2. One such activity was "think/pair/share" 10 during which students solved a problem individually, and then compared their answer with a classmate's. Other activities included "acting out oxidative phosphorylation", which over one third of the students (37\%) stated was their favorite activity. Many students enjoyed discussing clinical applications such as potential disease treatments, while other students felt the opportunity to work in teams was the best part of Molecules and Cells.

Table 2

Student Comments on Favorite Class Activities My favorite activity was the class reenactment of the electron transport chain. My favorite activity was the live demonstration of the ETC (electron transport chain). It included audience participation and gave a good visualization to an important concept. My favorite MoleCell activity this semester was just having a team to work with on activities (not necessarily the quizzes). It was nice to have a group of classmates I could talk to and consult in class and sometimes outside as well.

I enjoyed when we talked about diseases in more depth. I also really liked learning about the different signal pathways and how certain breakdowns in the pathways can lead to various diseases.

Cancer topics very interesting and relevant.

I loved the clicker questions - it really helped with learning and understanding the material.

In fact, almost two-thirds of the students in the class arranged study groups which met outside of class which could be viewed as a reflection of the student's perceived value of this activity. Another popular class activity was celebrating Noble Prize week in October, which involved announcing each day's winner, their research, and relevance to the course. Even though lectures were recorded, last fall over $90 \%$ of the students $(n=126)$ still came to lecture each day. We believe that the quality and value of the classroom experience prevented a drop in attendance, a problem that seems to be of national concern.

Weekly Team Based Learning (TBL)

There has been substantial research documenting the value of team based learning on student understanding and comprehension ${ }^{4,11}$. However, team based learning is only effective if each member of the team is prepared for the group discussion. Molecules and Cells students hand in homework on Thursday and are given the opportunity to discuss their solutions during TA-led Thursday sections prior to the Friday morning team based learning exercise. Students start the Friday class by taking a ten minute, ten question, multiple choice test (iRAT-individual Readiness Assessment Test) which has been designed to challenge the students on the material 
covered that week. After students hand in their iRAT, they complete the same ten question quiz as a team (gRAT-group Readiness Assessment Test). The student iRAT/gRAT scores clearly demonstrated the effectiveness of team based learning. In a class of 137 students, the average iRAT grade over the fall semester ( 9 quizzes) was $65.3+/-21.8$, while the average gRAT grade was $89.9+/-14.5$, significantly higher $(\mathrm{p}<0.0001)$. The student's grade on the iRAT/gRAT section of the course was calculated $50 \%$ from the iRAT, and 50\% from the gRAT, thus students had an incentive to prepare for the TBL sessions. The gRATs are noisy, interactive sessions where each team member argues their reasoning for choosing one of the answers from a scratchoff sheet which provides immediate feedback. If the answer is incorrect, the team has an opportunity to continue their discussion until, through peer instruction, all members of the team understand the correct answer ${ }^{12}$. The result is that students leave the Friday sessions with a much deeper understanding of the material covered that week. TBL sessions give students who comprehend the material an opportunity to reinforce their understanding by assisting those students with questions and uncertainties. Students who did not initially understand the details benefit from the group debate. The majority of students (93\%) believed TBLs were a useful learning experience, which is consistent with the literature. Student comments on TBL are provided in Table 3.

Table 3

Student Comments on Team Based Learning

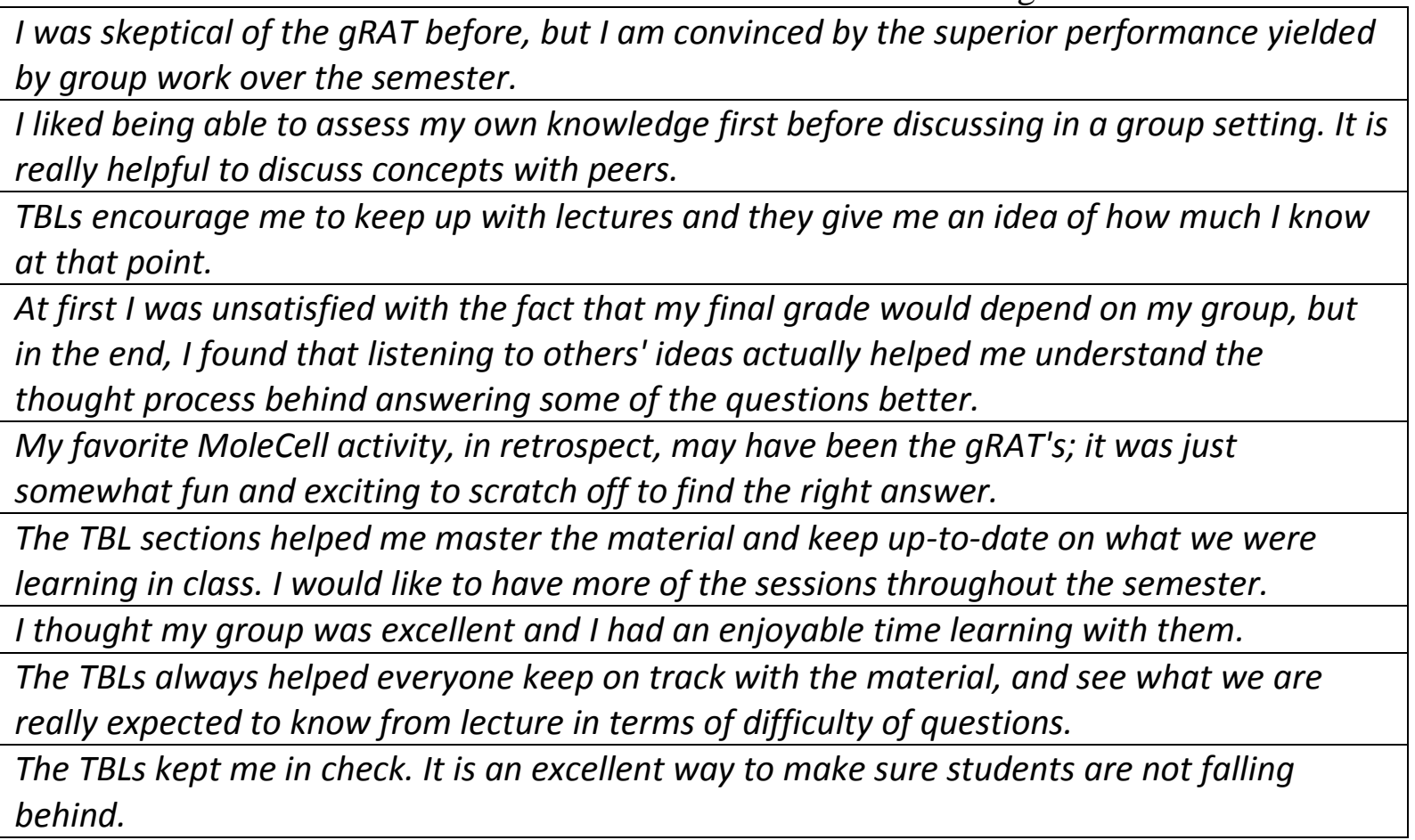

The remainder of the Friday class time was used for discussion of current research and clinical topics relating to that week's topics. Sample post-TBL discussion subjects have included impediments to the development of Ebola and Malaria vaccines, the immune response to sugars, and new treatments for cancer. The goal of these discussions was to use current events to bridge the gap between needed background information and real world applications. 


\section{Results and Summary}

The methods used to teach Molecules and Cells expose students to the same material multiple times, and in multiple different formats throughout the week. We have found this to be an effective teaching technique because it addresses the academic needs of students with diverse science backgrounds and diverse learning preferences. Students initially view videos or complete readings on their own to learn the main concepts. Class time covers equation derivations, current research, mathematical examples, and feedback in the form of clicker questions. Weekly team based learning quizzes reinforce key concepts while clinical case studies look at those concepts from a new perspective, motivating students to learn the details.

Because of this distributed learning method, by the time the students have an exam they have seen the material at least three times. Many students take advantage of opportunities to review the material many more times through the diverse array of online learning resources as well as practicing problems with a study group. One of the benefits of these efforts to offer multiple resources for students is so faculty can focus more time on applications and describing current research in the field, while still ensuring that students get the solid background they need for upper level courses. The average final grade for the class has remained around 77 (76.6 +/- 2.4, $\mathrm{n}=6$ years $)$, and the standard deviation has remained at $10(10.1+/-1.8)$ despite covering more material each year.

Implementing a multifaceted learning environment with a combination of visual, aural, $\mathrm{read} / \mathrm{write}$, and kinesthetic modes of learning, personalizes the learning experience so that each student has numerous methods to maximize their comprehension. We believe the high student attendance rate, positive course reviews, and successful student outcomes in the course support our hypothesis, both quantitatively and qualitatively, that a diverse learning environment provides students multiple opportunities for success.

References

(1) http://vark-learn.com/

(2) Caldwell, JE "Clickers in the Large Classroom: Current Research and Best-Practice Tips", (2007) 10.1187/cbe.06-12-0205 CBE Life Sci Educ Vol. 6 No. 1, 9-20 http://www.lifescied.org/content/6/1/9.full.pdf+html

(3) Tyler E. Mains, Joseph Cofrancesco Jr. MD, MPH, FACP, Stephen M. Milner, MB. BS. DSc, FACS, Nina G. Shah MS, Harry Goldberg, PhD. (2015) "Do questions help? The Impact of Audience Response Systems on Medical Student Learning". Postgraduate Medical Journal.

(4) Michaelsen, L.K., Watson, W.E., Cragin, J.P., and Fink, L.D. (1982) "Team-based learning: A potential solution to the problems of large classes". Exchange: The Organizational Behavior Teaching Journal 7(4): 18-33

(5) Richardson Lab, Kinemage http://kinemage.biochem.duke.edu/

(6) B. Alberts, D. Bray, A. Johnson, J. Lewis, M. Raff, K. Roberts, P. Walter (2009) Essential Cell Biology Garland Publishing, Inc., USA ( $3^{\text {rd }}$ edition)

(7) H. Lodish, A. Berk, S. L. Zipursky, P. Matsudaira, D. Baltimore, J. Darnell (2009), Molecular Cell Biology, W. H. Freeman and Co, USA, (6 ${ }^{\text {th }}$ edition)

(8) http://panopto.com/ 
(9) https://peerwise.cs.auckland.ac.nz/

(10) Kabalan, A (2014) https://www.asee.org/documents/sections/middle-atlantic/fall2014/Think_Pair_Share_A_Case_Study_in_an_Electrical_Engineering_Class.pdf

(11) Koles, PG, et al, (2010) "The Impact of Team-Based Learning on Medical Students' Academic Performance", Academic Medicine, Vol. 85, No. 11 / November 2010, 1739-1745

(12) Epstein, ML and Brosvic, GM, (2002) "Students Prefer the Immediate Feedback Assessment Technique", Psychological Reports, 90, 1136-1138

Acknowledgment

We would like to thank the Johns Hopkins University Center for Educational Resources for their financial support through multiple Technology Fellowships to develop online resources for Molecules and Cells. 